\title{
Information and capital flows: The determinants of transactions in financial assets
}

\author{
Richard Portes ${ }^{\mathrm{a}, \mathrm{b}, *}$, Hélène Rey ${ }^{\mathrm{c}, \mathrm{b}}$, Yonghyup $\mathrm{Oh}^{\mathrm{d}}$ \\ ${ }^{\mathrm{a}}$ London Business School, Regent's Park, London NW1 4SA, UK \\ ${ }^{\mathrm{b}}$ Centre for Economic Policy Research, London, UK \\ ${ }^{\mathrm{c}}$ Princeton University, Princeton, NJ, USA \\ ${ }^{\mathrm{d} C e n t r e ~ f o r ~ E c o n o m i c ~ P e r f o r m a n c e, ~ L o n d o n ~ S c h o o l ~ o f ~ E c o n o m i c s, ~ L o n d o n, ~ U K ~}$
}

\begin{abstract}
We show that a gravity model explains international transactions in financial assets at least as well as goods trade transactions. Our results support the hypothesis that informational asymmetries are responsible for the strong negative relationship between asset trade and distance. This result is very important for theories of asset trade, portfolio adjustments and home bias. We strengthen it by investigating the roles of explicit informational variables, as well as distance, in explaining separately cross-border trade in corporate equities, corporate bonds, and government bonds. (C) 2001 Elsevier Science B.V. All rights reserved.
\end{abstract}

JEL classification: F36; F21; F12; G111

Keywords: Capital flows; Cross-border portfolio investment; Information asymmetries; Gravity model; Geography

This paper confirms the result of our previous study (Portes and Rey, 2000): a gravity model ${ }^{1}$ explains international transactions in financial assets at least as

\footnotetext{
* Corresponding author. Tel.: + 44-20-7706-6886.

E-mail address: rportes@london.edu (R. Portes).

${ }^{1} \mathrm{~A}$ gravity model for trade is a model which explains trade flows between countries $i$ and $j$ by the two masses (GDPs) and distance. Extended versions include dummies for trade areas, cultural factors, etc.
} 
well as goods trade transactions. This may seem a surprising finding at first sight. Gravity models for goods trade have been estimated many times. They perform very well. Indeed, the gravity model is one of the best established empirical regularities in international economics.

Trade in assets has not been studied much empirically, however, and the models we would invoke to characterise it are a priori very different. For goods trade, distance has been always seen as a proxy for transportation costs and trade barriers (if they are proportional costs). And many models can justify the inclusion of the GDPs of the two countries in the regression. But financial assets are different. Nobody would deny that some measure of the size of the two countries involved should be included in the equation. But equities, bonds and other securities are pretty weightless. And as far as transaction costs are concerned, they seem very small, a few basis points, and not clearly connected with geographical features. Therefore, distance seems a highly improbable variable to encounter in a regression explaining asset trade.

Yet distance comes up remarkably strongly (with a negative sign) across all our specifications, so that the gravity model for asset trade seems as robust as the gravity model for international trade in goods. Since this result is very important for theories of asset trade, portfolio adjustments and home bias, it is worth exploring it further and trying to learn more from the data. If one believes that portfolio diversification models are appropriate to explain international transactions in assets, then one would think that, if anything, distance would tend to show up with a positive sign in asset trade regressions. Correlations between business cycles tend to decrease with distance. Therefore, if one wants to diversify portfolio holdings, one would tend to buy assets in countries which are far away.

What theory could then imply a strong negative correlation between asset trade and distance? The main hypothesis that comes to mind is that of asymmetric information. Distance is seen as a proxy for informational frictions: countries which are near each other tend to know much more about each other, either because of direct interaction between their citizens for tourism or business, or because of better media coverage, or because they tend to learn each other's languages.

If information asymmetry is the right assumption, then some other regularities should emerge from the data. One is that other variables proxying bilateral information flows more directly (but not too collinear with distance) should be significant and improve the fit of the regression. Second, disaggregated data across different financial assets with different informational contents should give us some clues. Trading in different financial assets implying a priori different intensities of information, distance should not be as significant, if at all, in a regression for treasury bonds as in a regression for portfolio equity flows or corporate bonds. Trading in the latter two assets should require 
Table 1

Bilateral equity transaction flows $1989-96^{\mathrm{a}}$

\begin{tabular}{lcccc}
\hline equityij & $(1)$ & $(2)$ & $(3)^{\mathrm{b}}$ & $(4)^{\mathrm{b}}$ \\
\hline mcapi & 0.993 & 0.997 & 1.006 & 1.010 \\
& $(0.030)$ & $(0.028)$ & $(0.058)$ & $(0.056)$ \\
mcapj & 1.060 & 1.089 & 1.077 & 1.106 \\
& $(0.031)$ & $(0.031)$ & $(0.058)$ & $(0.057)$ \\
distij & -0.881 & -0.707 & -0.890 & -0.717 \\
& $(0.031)$ & $(0.039)$ & $(0.063)$ & $(0.075)$ \\
telnorij & - & 0.181 & - & 0.177 \\
sophi & & $(0.027)$ & 0.627 & $(0.075)$ \\
sophj & $(0.034)$ & 0.466 & $(0.055)$ & 0.480 \\
& 0.248 & $0.039)$ & 0.265 & $(0.065)$ \\
$N$ & $(0.030)$ & $(0.037)$ & $(0.055)$ & $(0.119$ \\
$F(K, N-K-1)$ & 1456 & 1456 & 182 & 182 \\
$R^{2}$ & 352.58 & 334.38 & $189.74^{\mathrm{c}}$ & $173.43^{\mathrm{d}}$ \\
& 0.693 & 0.704 & $0.844^{\mathrm{e}}$ & $0.856^{\mathrm{e}}$ \\
\hline
\end{tabular}

${ }^{a}$ These regressions are based on the Portes and Rey (2000) data set. Coefficients on time dummies are not reported.

b'Between' regression on group means.

${ }^{\mathrm{c}} F(5,176)$.

${ }^{\mathrm{d}} F(6,175)$.

e'Between'.

deeper knowledge of the foreign economy, whereas treasury bonds are more homogeneous products, and the type of information needed to follow their evolution is a much narrower set of variables (typically, macroeconomic fundamentals).

In our previous study (Portes and Rey, 2000), we laid out carefully the stylised facts emerging from the data and carried out the first type of experiment. We estimated bilateral cross-border transactions in portfolio equities for 14 countries over 8 years (a panel of 1456 observations). The results of our benchmark regressions are reported in Table 1 . The market capitalizations in each country are 'scale' variables. The measures of 'financial market sophistication' represent direct transaction costs. We used the volume of telephone call traffic (normalized by the real GDPs of the two countries to remove pure size effects) as our information proxy. The correlation of this variable with distance is only -0.28 . Telephone call traffic reflects both a cost component of the information friction (price of calls) and a cultural one (privileged links between two countries, because of immigration, tourism, etc.). Our augmented regression with telephone calls performs better than the benchmark. Distance is not forced out, 
however, which suggests the relevance of several different channels of information flows.

In this paper, we conduct a further robustness check of the results described above, and we also take up the second experiment. We use a very different data set. We reran our regressions for portfolio equity flows including distance, phone calls, and the number of tourists of a given country visiting another. Our previous results were confirmed. We then took advantage of the disaggregation of the data set and ran separate regressions for portfolio equity, corporate bonds and treasury bonds. Again our results, which we will describe below, fit nicely with the hypothesis of informational asymmetries.

\section{How plausible are information asymmetries?}

Should we think that in our globalized world, information is flowing costlessly along our internet connections, and the relevant people responsible for asset trade are precisely the ones who also know how to launch their internet browsers? The information that is required to evaluate financial assets such as corporate bonds and equities is not straightforward and not equally available to all market participants. What is the relevant information? It ranges from knowing the accounting practices, the corporate culture, the political events, the current business conditions, to being able to foresee the feeling of exuberance following a victory in a football World Cup Championship. ${ }^{2}$

The literature seems to provide evidence of this type of information asymmetry. Hau (1999) shows that foreign traders make significantly less profit than German traders when they transact on the German stock market. He also finds weak evidence that German-speaking traders (in Germany and Switzerland) perform better than their non-German-speaking colleagues. Pagano et al. (1999) and Ahearne et al. (2000) underline the importance of the informational barriers constituted by different national accounting standards and practices.

Another relevant type of information for investors may be of a more strictly financial nature: how liquid is the market, who are the other investors participating, or what are the covariances of the assets. Access to that type of information is likely to differ across financial assets. There is not much mystery about the liquidity of the US T-bill market for example, and there are even academic data sets about it, featuring intradaily data on turnover, bid - ask spreads, etc. But other markets are far more opaque, and information about liquidity and price pressure comes through slowly, as transactions are made. Big players on

\footnotetext{
${ }^{2}$ Note of the French author: The example of the football European Championship could also have been used in a strictly similar way.
} 
a market will benefit from seeing first the order flows of their customers (see Lyons, 2000).

\section{Some remarks on the theory}

It is not difficult to write down a model deriving an equation for asset flows including the size of the two countries involved in international trade. Indeed any sensible model would have this. It is less trivial to analyse the impact of a friction on asset flows. For example, Martin and Rey (2001) model the friction as a proportional trading cost. The friction ends up reducing the flows between countries where viscosity is the highest. The difficulty remains, however - and it is a recurring problem for the finance literature (see Lyons (2000) for a comprehensive discussion) - how to account for the volumes exchanged on financial markets.

In a model for goods trade, goods are perishable and agents get utility each period by consuming new goods, which are imported or exported, hence there are continuous flows. But assets are not perishable. As long as the motive for transactions in assets is risk diversification as in international CAPM models or as in Martin and Rey (2001), then it is hard to generate continuous flows, unless a new cohort of investors comes in every period (trend growth of the economy), there is continuous arrival of information in a way that sustains the equilibrium informational asymmetry, or investors have heterogeneous beliefs. These alternatives are certainly well within the realm of plausibility. Although they may be a step in the right direction, however, they are probably not enough to generate the amazing turnover seen in our data and in all other financial market data. We will therefore take a very pragmatic view here and assert that whatever the motives for transactions in assets (diversification, speculative profits, reaction to news), the pattern of transactions seems to be shaped robustly by the friction itself (informational asymmetry). We plan in subsequent work to link our empirical results on flows to empirical results on asset holdings, in order to guide further our theoretical work.

\section{Empirical strategy and data}

Our empirical work investigates the conjecture that the information available to foreign transactors and its relevance to decisions to transact will differ across three different types of securities: corporate equities, corporate bonds, and government bonds. We therefore study cross-border transactions in those three categories of securities, using comparable data. As in Portes and Rey (2000), our dependent variable is the gross flow of transactions per period: purchases plus sales. 
Table 2

Foreign residents' transactions in US corporate equities, 1988-98

\begin{tabular}{lcccc}
\hline cstock & $(1)$ & $(2)$ & $(3)^{\mathrm{a}}$ & $(4)^{\mathrm{a}}$ \\
\hline fw & 0.605 & 0.650 & 0.709 & 0.810 \\
& $(0.069)$ & $(0.066)$ & $(0.114)$ & $(0.120)$ \\
dist & -1.273 & -0.934 & -1.200 & -0.812 \\
& $(0.096)$ & $(0.139)$ & $(0.380)$ & $(0.120)$ \\
telavn & - & 0.275 & - & 0.452 \\
& & $(0.099)$ & 0.623 & $(0.222)$ \\
soph & 0.633 & 0.586 & $(0.136)$ & 0.537 \\
& $(0.046)$ & $(0.045)$ & 39 & $(0.139)$ \\
$N$ & 385 & 372 & $34.15^{\mathrm{b}}$ & 39 \\
$F(K, N-K-1)$ & 55.85 & 54.40 & $0.745^{\mathrm{d}}$ & $28.05^{\mathrm{c}}$ \\
$R^{2}$ & 0.681 & 0.695 & $0.768^{\mathrm{d}}$ \\
\hline
\end{tabular}

a'Between' regression on group means.

${ }^{\mathrm{b}} F(3,35)$.

${ }^{\mathrm{c}} F(4,34)$.

d'Between'.

We use bilateral flows between the US and a set of 40 advanced and emerging markets. These are extracted from the US Treasury TIC data, ${ }^{3}$ which measure transactions in US and foreign equities between US and foreign residents. They are collected monthly, but most of our explanatory variables are available only annually, so we are constrained to use annual data for 1988-1998. There are, however, some missing observations, so the total number of observations used in any regression ranges from 168 to 385 (when we pool the data). Also, whereas foreign residents' transactions in US bonds are broken down in the data as between corporate and government bonds, the converse is not true: the data aggregate US residents' transactions in foreign bonds to include all bonds for each foreign country.

We report four regressions for each type of security and residency of the transactor (US or foreign). Tables 2-4 deal with foreign residents' transactions in US markets, Tables 5 and 6 with transactions abroad by US residents. The first regression in each of Tables 2-4 explains total transactions as a function of the foreign country's financial wealth (a 'scale' variable), the distance between New

\footnotetext{
${ }^{3}$ One shortcoming of these data is that they recognize only the country of the foreign transactor, not of the foreign equity. For a more detailed description of these data see Warnock and Mason (2000). They suggest that the financial centre activities of London and Hong Kong result in significant overstatement of transactions volumes for those countries, so we tried using dummy variables for each in our regressions. The dummy for the UK was generally significant, that for Hong Kong was not; but the estimates of the other coefficients were unaffected.
} 
Table 3

Foreign residents' transactions in US corporate bonds, 1988-98

\begin{tabular}{lcccc}
\hline cbond & $(1)$ & $(2)$ & $(3)^{\mathrm{a}}$ & $(4)^{\mathrm{a}}$ \\
\hline fW & 0.624 & 0.680 & 0.691 & 0.779 \\
& $(0.076)$ & $(0.069)$ & $(0.138)$ & $(0.143)$ \\
dist & -1.291 & -0.930 & -1.307 & -0.829 \\
& $(0.147)$ & $(0.185)$ & $(0.458)$ & $(0.509)$ \\
telavn & - & 0.324 & - & 0.429 \\
& & $(0.100)$ & & $(0.261)$ \\
soph & 0.514 & 0.460 & 0.516 & 0.442 \\
& $(0.054)$ & $(0.052)$ & $(0.164)$ & $(0.164)$ \\
$N$ & 376 & 365 & 39 & 39 \\
$F(K, N-K-1)$ & 26.26 & 28.00 & $20.72^{\mathrm{b}}$ & $17.20^{\mathrm{c}}$ \\
$R^{2}$ & 0.559 & 0.582 & $0.640^{\mathrm{d}}$ & $0.669^{\mathrm{d}}$ \\
\hline
\end{tabular}

a 'Between' regression on group means.

${ }^{\mathrm{b}} F(3,35)$.

${ }^{\mathrm{c}} F(4,34)$.

d'Between'.

York and the financial centre of the foreign country, ${ }^{4}$ and an index of the 'sophistication' of the foreign country's financial sector (a proxy for the transaction technology). This regression pools all the available observations, and we therefore include dummy variables for each year. As an alternative, we tried a linear time trend, but it was insignificant throughout. One consequence of using the dummy variables for each year is that we cannot use US financial wealth as a second scale variable, because the year dummies will absorb its effect. Our measure of the foreign country's financial wealth is the sum of the market capitalization of its equity, bond markets and bank claims. Because of missing observations, in some cases we have had to estimate this variable (see Appendix). Here and elsewhere we do not report coefficients on the year dummies or the constant term.

The second regression, also pooled with year dummies, adds an explicit information variable, telephone call traffic. ${ }^{5}$ We take the total volume of calls (in minutes) between the two countries, regardless of the origin of the call, and we normalize it by dividing by the square root of the product of the two real GDPs to remove the size effects. We were not able to extend to this larger group of countries the variable representing bank branches that we used in the previous paper. Nor do we use here a variable representing the degree of insider trading in

\footnotetext{
${ }^{4}$ We tried the difference in longitude and the difference in latitude separately, but neither was significant.

${ }^{5}$ It might be thought that the telephone call traffic between two countries would be closely related to the distance between them - in fact, however, the simple correlation is only -0.30 .
} 
Table 4

Foreign residents' transactions in US treasury bonds, 1988-98

\begin{tabular}{lcccc}
\hline treab & $(1)$ & $(2)$ & $(3)^{\mathrm{a}}$ & $(4)^{\mathrm{a}}$ \\
\hline fw & 0.746 & 0.810 & 0.833 & 0.929 \\
& $(0.117)$ & $(0.104)$ & $(0.184)$ & $(0.195)$ \\
dist & -0.601 & -0.277 & -0.541 & -0.159 \\
& $(0.136)$ & $(0.206)$ & $(0.614)$ & $(0.703)$ \\
telavn & - & 0.358 & - & 0.412 \\
& & $(0.144)$ & & $(0.362)$ \\
soph & 0.431 & 0.383 & 0.400 & 0.318 \\
& $(0.072)$ & $(0.070)$ & $(0.220)$ & $(0.227)$ \\
$N$ & 383 & 371 & 39 & 39 \\
$F(K, N-K-1)$ & 16.55 & 18.02 & $11.54^{\mathrm{b}}$ & $9.37^{\mathrm{c}}$ \\
$R^{2}$ & 0.454 & 0.474 & $0.497^{\mathrm{d}}$ & $0.524^{\mathrm{b}}$ \\
\hline
\end{tabular}

a 'Between' regression on group means.

${ }^{\mathrm{b}} F(3,35)$.

${ }^{\mathrm{c}} F(4,34)$.

d'Between'.

Table 5

US residents' transactions in foreign corporate equities, 1988-98

\begin{tabular}{lcccc}
\hline fstock & $(1)$ & $(2)$ & $(3)^{\mathrm{a}}$ & $(4)^{\mathrm{a}}$ \\
\hline scap & 0.925 & 0.959 & 0.933 & 0.943 \\
& $(0.030)$ & $(0.032)$ & $(0.101)$ & $(0.100)$ \\
dist & -0.826 & -0.795 & -0.836 & -0.763 \\
& $(0.103)$ & $(0.132)$ & $(0.241)$ & $(0.285)$ \\
telavn & - & -0.041 & - & -0.002 \\
& & $(0.071)$ & & $(0.140)$ \\
soph & 0.202 & 0.183 & 0.165 & 0.150 \\
& $(0.038)$ & $(0.051)$ & $(0.095)$ & $(0.115)$ \\
insiders & - & -0.292 & -0.037 \\
& & $(0.049)$ & & $(0.132)$ \\
$N$ & 358 & 304 & 35 & 34 \\
$F(K, N-K-1)$ & 150.43 & 121.77 & $52.94^{\mathrm{b}}$ & $32.57^{\mathrm{c}}$ \\
$R^{2}$ & 0.822 & 0.831 & $0.837^{\mathrm{d}}$ & $0.853^{\mathrm{d}}$ \\
\hline
\end{tabular}

a 'Between' regression on group means.

${ }^{\mathrm{b}} F(3,31)$.

${ }^{\mathrm{c}} F(5,28)$.

d'Between'.

US securities markets - it does not vary substantially over the sample period. In any case, the year dummies would obscure its effect as well.

In these regressions, the dependent variable, distance, and telephone traffic are all in logs; financial sector sophistication is in its original index number form. 
Table 6

US residents' transactions in foreign bonds, 1988-98

\begin{tabular}{lcccc}
\hline fbond & $(1)$ & $(2)$ & $(3)^{\mathrm{a}}$ & $(4)^{\mathrm{a}}$ \\
\hline bcapi & 0.328 & 0.236 & 0.334 & 0.259 \\
& $(0.082)$ & $(0.084)$ & $(0.163)$ & $(0.165)$ \\
dist & -0.795 & 0.096 & -0.758 & 0.036 \\
& $(0.159)$ & $(0.186)$ & $(0.635)$ & $(0.690)$ \\
telavn & - & 1.078 & - & 1.030 \\
& & $(0.131)$ & 0.664 & $(0.434)$ \\
soph & 0.604 & 0.458 & $(0.221)$ & 0.429 \\
insiders & $(0.087)$ & $(0.082)$ & - & $0.287)$ \\
& - & -0.017 & & 0.054 \\
$N$ & & $(0.100)$ & 22 & $(0.402)$ \\
$F(K, N-K-1)$ & 168 & 146 & $5.86^{\mathrm{b}}$ & 22 \\
$R^{2}$ & 14.42 & 30.06 & $0.494^{\mathrm{d}}$ & $5.53^{\mathrm{c}}$ \\
& 0.449 & 0.605 & & $0.633^{\mathrm{d}}$ \\
\hline
\end{tabular}

\footnotetext{
a 'Between' regression on group means.

${ }^{\mathrm{b}} F(3,18)$.

c'Between'.

${ }^{\mathrm{d}} F(5,16)$.
}

The third and fourth columns of Tables 2-6 give the 'between' regression (on group means) corresponding to columns (1) and (2).

\section{Results}

The results reported in Table 2, for foreign residents' transactions in US equities, are almost as good as those in Table 1, although we have substantially fewer observations. They are indeed strikingly similar to what we found in the previous paper, using a quite different data set. The elasticities on both distance and telephone traffic, at -0.9 and 0.2 , respectively, in the pooled regressions, are somewhat higher than in Table 1; they are less precisely estimated, but still strongly significant. The coefficient on financial sector sophistication is very close to that estimated in Table 1 . The overall goodness of fit of these regressions is remarkably strong - with four explanatory variables, we are capturing $70 \%$ of the variance of transactions flows in the pooled regressions, and the 'between' $R^{2}$ s are 0.84 and 0.86 . Almost all the explanatory power comes in cross-section rather than time series, which makes these statistics all the more remarkable. ${ }^{6}$

\footnotetext{
${ }^{6}$ The elasticity of the volume of transactions by foreigners in US stock markets with respect to the total US stock market capitalization is very close to unity. We therefore ran the regressions of Table 2 normalizing the dependent variable on US market capitalization; neither the goodness of fit nor the estimated coefficients were significantly different.
} 
The results for foreign residents' transactions in US corporate bonds, in Table 3, are in turn surprisingly similar to those in Table 2. The estimated coefficients for bonds are statistically indistinguishable from those for equities! ${ }^{7}$ The fit is somewhat less good, but it is clear that our conjecture is not confirmed by these estimates: the information variables appear to play the same role for both types of securities. Note that we would a priori have expected that both equities and corporate bonds require a lot of information for their trade and that this information is unlikely to be equally available to foreign and domestic investors. It was not obvious, however, that these two type of securities would be equally information intensive.

For both categories of securities, we tried a dummy variable for English language (both broad and 'restricted' subsets of countries - see Appendix). This dummy variable was not significant.

The picture changes in Table 4, in accordance with our conjecture. Foreign residents' transactions in US government bonds do not show the same influence of the information variables that we found for corporate securities. Here, moreover, the English language dummy is significant, but it does not affect the estimates for the other coefficients. The regressions are distinctly weaker than in Tables 1-3. Foreign financial wealth still enters strongly. But although the coefficients on the other explanatory variables take the expected signs, the elasticity on distance falls and becomes insignificant when the telephone traffic variable enters, and the latter becomes insignificant in the 'between' regressions. The financial sector sophistication variable shows up well in the pooled regressions but not in the 'between' regressions. This result accords very well with our prior that government bonds (especially US ones) are relatively homogeneous assets for which informational asymmetries are not very relevant. One potentially important factor here may also be the role of foreign central banks in cross-border trade in US Treasury securities - we might expect managers of foreign exchange reserves to behave differently from private investors. The data do not permit isolating this component.

Our results for US residents' transactions in foreign markets are presented in Tables 5 and 6 . These tables are organized similarly to Tables $1-4$. Trade in foreign corporate equities by US residents is first regressed on the foreign country's stock market capitalization (beginning-of-year), distance, and the index of sophistication of the foreign country's financial sector, pooling all observations and using dummy variables for the years. Then we introduce telephone call traffic and an index of the 'perceived absence of insider trading' in each of the foreign (non-US) markets (defined this way, we expect it to enter with a positive coefficient). The dependent variable and the first three explanatory variables are in logs. In Table 6, we repeat the same procedure for trade in

\footnotetext{
${ }^{7}$ This is confirmed by a Wald test.
} 
foreign bonds (the sum of corporate and government bond transactions volumes), but using total bond market capitalization as the scale variable.

For trade in equities, stock market capitalization takes an elasticity close to unity. Distance enters consistently with an elasticity of -0.8 , slightly lower than that for foreign trade in US equities. Financial market sophistication takes a smaller coefficient than in Table 2 , still positive, but significant only in the pooled regressions. Here, however, the telephone traffic variable is hardly visible. Nor does the insider trading variable have any explanatory power. But market cap and distance together pick up over $80 \%$ of the variance in equity trade, and overall, the results for US investors look fairly similar to those for non-US investors.

As we might suppose - if only because of the aggregation of corporate and government bonds - the results in Table 6 are relatively weak. This is the only case so far in our work where distance appears not to be significant (except in column (1)) - indeed, it takes a positive coefficient in the regressions with telephone traffic, which however appears fairly strongly. Financial market sophistication plays a significant role; insider trading does not. The $R^{2}$ s are respectable but substantially lower than in the previous tables.

Finally, we investigated total tourist traffic (the sum of number of US tourists going to the foreign country and the reverse flow) as a variable representing information transmission. But the simple correlation between this and the telephone traffic variable is 0.87 . Not surprisingly, the tourism variable does as well as telephone calls, but not significantly better, and the two together generate unstable coefficients.

\section{Conclusions}

Our results confirm the robustness of the stylized facts uncovered in Portes and Rey (2000) using a completely different data set. It is indeed the case that the gravity model performs at least as well for trade in assets as for trade in goods. They also confirm that distance seems to enter as a proxy for informational asymmetries, since our telephone traffic variable and our tourism variable perform very well in our regressions. Moreover, using disaggregated data on trade in different financial assets requiring a priori different informational contents turned out to be very useful. As expected, transactions in corporate bonds and equities are much more information intensive than transactions in treasury bonds. To our (slight) surprise, however, transactions in corporate bonds and equities seem to involve the same degree of informational asymmetries.

In future work, we plan to extend this analysis to cross-border bank loans and to foreign direct investment. We shall also introduce variables representing risk diversification to try to get at the underlying transaction motives. We will also 
investigate the determinants of asset holdings in order to compare them with our results on flows, so that a coherent theory of asset trade can be constructed which should take full account of the viscosities of the so-called global international capital market.

\section{Acknowledgements}

Portes is grateful for the hospitality of the Haas Business School (University of California, Berkeley) and support of its Clausen Center. Rey thanks the Department of Economics, University of California, Berkeley, for hospitality and support, as well as the Centre for Economic Performance, London School of Economics. We have benefited from comments by participants in the August workshop of the Clausen Center and the Federal Reserve Bank of San Francisco, as well as comments in the EEA session. Sonia Muñoz provided outstanding research assistance.

\section{Appendix: Data}

Purchases and sales of US and foreign securities between the US and foreign residents

US Treasury (http://www.treas.gov/tic/index.htm).

Financial wealth

Financial wealth $=$ bond market capitalization (corporate and government) + stock market capitalization + bank claims.

Since there are many missing values for financial wealth, we constructed a new financial wealth variable. We regressed (using a 'between' estimator) financial wealth on nominal GDP and our sophistication variable for the 20 countries for which there is no missing value; these countries include both developed countries and emerging markets.

Financial wealth $=1.068$ nomGDP $\quad+0.301$ sophi $\quad-22.71$

$$
(0.110) \quad(0.090)
$$

$R^{2}=0.869, N=143$.

We then used this relation to calculate financial wealth in our sample. For all our regressions we used the constructed variable (tables reported), and we checked that the results with the real variables were consistent.

Telephone traffic

Source: International Telecommunications Union. 


\section{Distance}

Source: Shang Jin Wei web site (http://www.ksg.harvard.edu/people/sjwei).

Degree of insider trading

Source: World Competitiveness Yearbook, IMD (or http://www.imd.ch/wcy/ wcy.cfm).

The higher the index figure is, the less common is the insider trading in the stock market.

\section{Sophistication of financial market}

Source: World Competitiveness Yearbook, IMD.

Note: For insiders and soph variables, missing values are replaced by nearest figures, e.g. if only 1993, 1994 values are available for a country, then the values for the previous years before 1993 are same as that of 1993 . The values for the years after 1994 are same as that of 1994.

Stock market capitalization (value at the beginning of the year)

Source: Datastream.

Bond market capitalization (value at the beginning of the year)

Government bonds and corporate bonds.

Source: Size and Structure of the World Bond Market: 2000, Merrill Lynch.

Price index $(C P I)$

Source: IFS.

Number of bilateral tourists

Source: World Tourism Organization (http://www.world-tourism.org).

English language dummy

We used two versions: 'restricted', in which only the US, UK, Canada, Australia and Ireland were included; and a broader set, which added Hong Kong, India, Singapore and South Africa.

\section{References}

Ahearne, A., Griever, W., Warnock, F., 2000. Information costs and home bias: An analysis of US holdings of foreign equities, manuscript. Federal Reserve Board, Washington DC, August.

Hau, H., 1999. Evidence on the information geography of a stock market. Discussion paper no. 2297. CEPR, London.

Lyons, R., 2000. The Microstructure Approach to Exchange Rates. At www.haas.berkeley.edu/ lyons. MIT Press, Cambridge, MA, forthcoming.

Martin, P., Rey, H., 2001. Financial supermarkets: Size matters for asset trade. Revised version of CEPR Discussion paper 2232.

Portes, R., Rey, H., 2000. The determinants of cross-border equity flows: The geography of information. Revised version of CEPR Discussion paper 2225, January. 
Pagano, M. et al, 1999. The geography of equity listing: Why do European companies list abroad? Working paper no. 28. Center for Studies in Economics and Finance, University of Salerno. Warnock, F., Mason, M., 2000. The reliability of U.S. data on transactions in foreign equities, Manuscript. Federal Reserve Board, Washington, DC, August. 